\title{
A técnica logística no toyotismo: uma aproximação geográfica do just-in-time
}

André Simplício Carvalho UFMG

p. $32-47$

\section{revista}

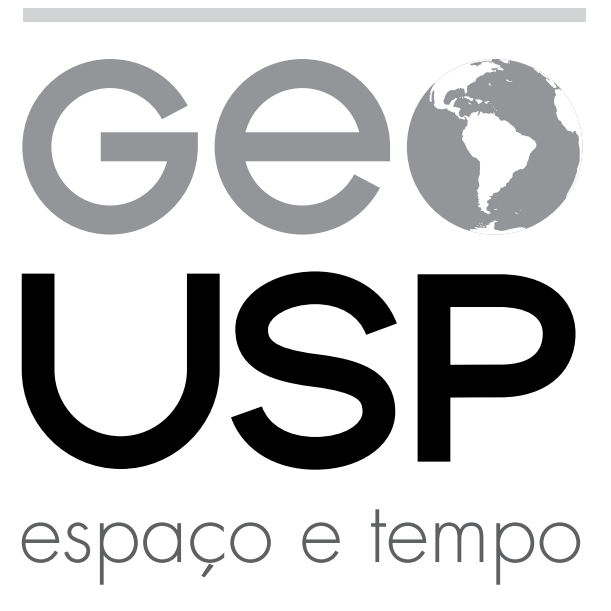

Volume $21 \cdot n^{\circ} 1(2017)$

ISSN 2179-0892
Como citar este artigo:

CARVALHO, A. S. A técnica logística no toyotismo: uma aproximação geográfica do just-in-time. Geousp-Espaço e Tempo (Online), v. 21, n. 1, p. 32-47, abril. 2017. ISSN 21790892

Disponível em: $<\underline{h t t p: / / w w w . r e v i s t a s . u s p . b r / g e o u s p /}$ article/view/96023 > doi: 10.11606/issn.2179-0892. geousp.2017.96023.

\section{(c) $(1) \Theta$}

Este artigo está licenciado sob a Creative Commons Attribution 4.0 License. 


\title{
A técnica logística no toyotismo: uma aproximação geográfica do just-in-time
}

\section{Resumo}

Entre outros sistemas de ordenamento logístico, o just-in-time é muito citado por geógrafos dedicados a estudos sobre economia e transporte - especialmente no contexto do toyotismo -, mas pouco esclarecido. Assim, propõe-se neste artigo esclarecer o que é exatamente o just-intime, contextualizando-o no âmago das mudanças do processo produtivo que consolidou a globalização a partir da década de 1970, ensejando sua aproximação geográfica. Essa aproximação permite interpretar o just-in-time como uma técnica de ordenamento de fluxos que se revela no espaço como uma rede, ordenada por uma lógica produtiva de desperdício zero.

Palavras-chave: Just-in-time. Globalização. Toyotismo. Técnica. Redes.

\section{The logistic technique in the toyotism: a geographic approach on Just-in-Time}

\begin{abstract}
The Just-in-Time, among other logistical systems, it is much quoted by geographers dedicated to economic and transportation studies, especially in the context of Toyotism, but very little understood. Thus, we propose in this article explain what exactly Just-in-Time is, contextualizing it in the heart of the production process changes that allowed the consolidation of globalization since the 1970s, to thereby provide a geographical approach on the same. This approach allows to interpret the Just-in-Time as a flow planning technique that reveals itself in space as a network. Network this orientate to a zero waste production.
\end{abstract}

Keywords: Just-in-Time. Globalization. Toyotism. Technic. Networks. 


\section{Introdução}

Atualmente, os diversos territórios do planeta se encontram em um nível inédito e crescente de integração econômica, uma verdadeira sincronização das economias nacionais às forças dominantes do capitalismo, de tal maneira que eventos ocorridos em lugar ou país específicos afetem outras economias em pontos opostos do planeta. Essa força de sincronia é permitida, na visão de Milton Santos, por uma unicidade técnica. Técnicas essas que não se dão isoladamente e tendem a influenciar até mesmo as técnicas mais arcaicas (Santos, 2000). Entre essas diversas técnicas que permitem a globalização se encontram as dos sistemas de informação, transporte, produção e as de gestão (Coutinho, 1995; Harvey, 1992; Moreira, 2007; Santos, 2009; Tavares, 1995).

As técnicas de transporte e difusão de informação são as maiores responsáveis pela integração econômica dos mercados nacionais; tanto de um ponto de vista imaterial, por fluxos de capitais, informações e produtos financeiros, como material, produtos de todo tipo e em todo nível de acabamento deslocado de um canto para outro do planeta, num sistema de mercado cada vez mais complexo (Corrêa, 1997; Harvey, 1992; Santos, 2009). Conforme essas técnicas de transporte ganharam importância para o sistema capitalista como um todo, a fim de viabilizar a maximização do lucro, a academia e a tecnocracia também voltam parte de suas atenções para o que ficou conhecido pelo binômio transporte e logística, compreendendo-se aqui que o transporte "constitui uma função fundamental na logística da cadeia de abastecimento" (Coró, 2003, p. 110).

A logística que para Silveira (2011) seria tão antiga quanto o próprio ato de transportar e que para Sutherland (2009) seria tão antiga quanto a necessidade de suprir, movimentar e manter forças armadas, só foi efetivamente sistematizada e nominada na França por volta de 1873 no âmago das forças militares daquele país (Silveira, 2011). Seu estabelecimento como campo de conhecimento se dá só 1963, com a formação do National Council of Physical Distribution Management e sendo mais abordada por geógrafos a partir da década de 1970, dentro da especialização geografia dos transportes ou da mobilidade (Pons; Bey; Beynés, 2011).

Logística essa que pode ser esquematicamente entendida como a "eficiente transferência de bens da fonte de suprimento ao local de manufatura até o ponto de consumo de uma forma custo-eficiente visando prover um serviço aceitável ao consumidor" (Rushton; Croucher; Baker, 2010, p. 6), tem entre suas formas de ordenamento mais sofisticado e difundido dessa virada de século está o Just-in-Time ${ }^{1}$ (JIT) concebido no Japão, em oposição ao just-in-case fordista, e que tem se difundido pelo mundo nas últimas quatro décadas, juntamente com outros aspectos do toyotismo. É sobre essa concepção de ordenamento logístico, o JIT, que iremos discorrer aqui tentando trazer uma contribuição em dois sentidos.

A primeira contribuição vai no sentido de elucidar a diferença, e a relação, entre

1 Em tradução livre, "na hora certa" ou "no momento exato". 
JIT e o toyotismo (modelo Toyota de produção), tendo em vista que apesar de muitos trabalhos citarem o primeiro termo (Coutinho, 1995; Mccann, 2008; Santos, 2009; Wood, 1992) ou tomarem os dois como sinônimos (Hutchins, 1993) não se preocupam em esclarecer o leitor sobre o tema. Esse fato induz o leitor a tratar JIT como sinônimo do toyotismo, ou acumulação flexível, quando, na verdade, este representa apenas um dos aspectos do modelo. Uma segunda contribuição vai no sentido de interpretar o JIT como fenômeno espacial e, portanto, passível de uma interpretação geográfica, uma tentativa de aproximação geográfica. Por fim vamos enfatizar os principais aspectos levantados acerca do nosso objeto em relação ao espaço na globalização.

\section{Contextualizando as transformações no sistema produtivo global e o surgimento do just-in-time}

A técnica do JIT é um modo de ordenamento logístico que não surgiu como uma inovação primeira, ou fruto de uma nova e revolucionária tecnologia de transporte, mas surge como um dos elementos de uma inovação maior, uma modificação mais estrutural no sistema produtivo que se inicia no Japão no final da década de 1950 e começa ganhar o mundo especialmente no final da década de 1980.

Essa transição é caracterizada por Harvey (1992) e Benko (1996) pela saída do modelo fordista de produção em massa da condição de modelo produtivo hegemônico, dando lugar a outros modelos de produção caracterizados em seu conjunto como pósfordistas ou de acumulação flexível, entre outros nomes. Compreende-se aqui modelo produtivo hegemônico não como um modelo único a todos os sistemas fabris no mundo, mas sim o modelo produtivo que é capaz de gerar maior acumulação e giro de capital dentro do sistema capitalista em um determinado contexto histórico econômico. Assim, como modelo de produção hegemônico funciona concomitantemente com outros modelos fabris, prova disso é a persistência de modelos de produção artesanal que convivem no mesmo mundo de fábricas altamente robotizadas.

Para bem compreender o quão revolucionário foi o processo em que o JIT surgiu se faz necessário entender um pouco melhor do que se tratava o modelo que vigorava até então como hegemônico, o fordismo.

\section{Fordismo}

O modo como o sistema fordista se estabeleceu constituí, com efeito, uma longa e complicada história que se estende por quase meio século, isso dependeu de uma miríade de decisões individuas, corporativas, institucionais e estatais, muitas delas escolhas políticas feitas ao acaso ou respostas improvisadas às tendências de crise do capitalismo, particularmente em sua manifestação na Grande Depressão dos anos 1930 (Harvey, 1992, p. 122123). 
O modelo fordista, assim como seu sucessor, nasce na indústria automobilística antes de ganhar as fábricas dos outros setores da economia. Ele, o fordismo, veio para substituir um modelo quase artesanal da produção de carros em que as plantas eram pequenas, com um gerenciamento direto do proprietário sobre todos os aspectos da produção e venda, uma mão de obra altamente qualificada, que por vezes abriam seus próprios negócios, um elevado custo e baixa qualidade final dos carros produzidos. Esses produtos só eram acessíveis às pessoas de alta renda e eram montados um a um, pois ainda se tratava de uma inovação tecnológica, e não se dispunha do mesmo nível de automação e demanda dos produtos têxteis, por exemplo.

Henry Ford (1988), neste contexto, trabalha para complementar as ideias expostas por Taylor nos princípios gerais de administração, ao conceber a noção de produção de massa e linha de produção. Para operacionalizar a produção em massa e, consequentemente, o consumo em massa, iniciou a introdução de novas formas de ordenar a produção de seus carros. Essas mudanças passavam pela especialização funcional de cada um dos trabalhadores da fábrica; desde os setores de gerência ao chão da fábrica, cada qual agora desempenharia uma tarefa que requer um número significativamente menor de habilidades.

Na planta, instalou-se uma linha de montagem em que o "trabalho" chegava a cada trabalhador responsável por montar uma única parte do veículo e seguia adiante. $\mathrm{O}$ resultado foi que a velocidade de saída de um modelo Ford passasse de 12h28, em 1913, para 1h30, em 1914 (Gartman apud Benko 1996, p. 117). Essas tarefas eram executadas durante oito horas de trabalho, exigindo assim do trabalhador mais disciplina do que anteriormente. A implantação desse modelo não veio sem resistência, implicando numa alta rotatividade da mão de obra nas indústrias Ford. Resistência que também se dará na implantação do toyotismo, posteriormente.

$\mathrm{Na}$ forma de gerir o conjunto da empresa fez-se um esforço para uma integração vertical rígida, que envolvia a criação ou aquisição de outras plantas que fizessem algum material necessário à montagem dos carros. Exemplo expoente desse impulso de integração vertical foi a criação da Fordlândia no coração da Floresta Amazônica, que tinha por objetivo produzir látex para os componentes automotivos, especialmente para pneus. Além da integração vertical, a empresa como um todo trabalhava com grandes estoques e uma alta produtividade que tinha por objetivo o consumo de massa de produtos padronizados, como o conhecido Modelo T, primeiro carro a ser popularizado graças as reformas de Ford.

Como já coloca Liker (2005), o modelo de Ford se assentava em economias de escala, um mercado consumidor abundante e uma grande disponibilidade de mão de obra. Tudo era padronizado e feito em grandes quantidades. Era um modelo que permitia superprodução e manutenção de largos estoques, as perdas e defeitos ao longo do processo de produção eram escamoteadas pelo grande volume.

As mudanças profundas propostas pelo novo sistema não se consolidaram sozinhas, foi necessária uma reorientação, dessa vez no Estado, para que o fordismo pudesse 
prosperar e se consolidar nos diversos setores das economias ocidentais. Esse novo elemento foi trazido pelas ideias de John Mayard Keynes, o keynesianismo, adotadas pelos EUA pelo New Deal de Roosevelt. O keynesianismo envolvia um estrito controle do Estado sobre as forças produtivas e pregava o bem-estar social, o "Estado providência". As reformas de Roosevelt se encaixaram muito bem com as de Ford, permitindo assim a implantação de uma sociedade de produção e consumo e massa, especialmente de bens de consumo duráveis, que foi consolidado pela Segunda Guerra Mundial, quando se fez necessário um gigantesco esforço produtivo de massa para o abastecimento das tropas aliadas.

O sistema produtivo fordista-taylorista viu sua maturidade em 1945, e fez parte integral do American Way of Life difundido pelo mundo no pós-guerra. No entanto, ele se viu incapaz de continuar no fim da década de 1960. De modo mais geral, no período de 1965 a 1973 tornou cada vez mais evidente a incapacidade do fordismo e do keynesianismo de conter as contradições inerentes ao capitalismo. "Na superfície, essas dificuldades podem ser mais bem apreendidas por uma palavra: rigidez" (Harvey, 1992, p. 135).

A rigidez do fordismo estava tanto no ordenamento das empresas, verticalmente integradas e fortemente centralizadas, quanto nas linhas de produção rigidamente disciplinadas e organizadas, como também nas formas de investimento de longo prazo e larga escala. Essas características somadas ao grande poder dos sindicatos impedia a flexibilização e adaptação do sistema as novas condições. A crise dos anos de 1970, somada ao choque do petróleo em 1973, fez com que o modelo fordista começasse a ruir, forçando novas formas de organização.

As novas formas de organização do sistema produtivo capitalista não vieram de grandes planejamentos ou decisões tomadas pelas multinacionais em todo mundo, mas por uma série de opções isoladas que foram perseverando a fim de retomar-se o crescimento econômico e o lucro (Benko, 1996). As formas que começaram a vigorar a partir dos anos de 1970 eram opostas à rigidez do sistema fordista. A acumulação flexível veio como uma mudança de disposição das relações de produção e de trabalho, que terminaram na desintegração vertical das empresas, no aumento substancial dos processos e terceirização, subcontratação, contrato de autônomos, um aumento da rotatividade e ao mesmo tempo uma desintegração na empresa que solapava a capacidade de organização dos trabalhadores. Por outro lado, o progresso técnico e a informatização permitiram uma série de mudanças no processo produtivo.

O toyotismo será um dos sistemas produtivos mais bem-sucedidos dentro desse novo contexto e apresentará uma série de inovações que irão se difundir pelo mundo, entre elas o JIT. Faz-se necessário uma melhor compreensão do contexto de concepção do toyotimo para entendermos o que levou a criação e difusão do JIT.

\section{Toyotismo e a acumulação flexível}

A Toyota nasceu inicialmente como uma empresa de produção de teares automáticos, que derivou suas atividades para a produção automobilística e se encontrava 
em uma situação precária após a Segunda Guerra Mundial.

Kiichirõ Toyoda, ${ }^{2}$ então presidente da Toyota Motors Company, estava disposto a fazer acontecer a produção automotiva em larga escala no Japão, que ainda se recuperava da guerra. Ele, no entanto, lidava com alguns problemas específicos no seu país:

- o mercado doméstico era pequeno e exigia uma gama muito grande de tipos de produtos;

- a força de trabalho local não se adaptaria ao conceito taylorista;

- a compra de tecnologia no exterior era impossível; e

- a possibilidade de exportação era remota (Wood, 1992).

Toyoda reformulou as condições da linha de produção fordista à moda japonesa juntamente com seu engenheiro chefe, Taiichi Ohno. Visando sempre reduzir ao máximo os desperdícios de tempo, material e pessoal em sua unidade produtiva, os dirigentes da empresa começaram a implementar uma série de reformas ao mal copiado sistema fordista na empresa. Essas reformas buscavam reduzir pessoal, os problemas de estocagem e de montagem dos veículos, uma verdadeira "fordização" à japonesa que buscava alcançar em poucos anos um nivelamento com a indústria automobilística americana e conseguiu sua superação em poucas décadas. ${ }^{3}$ A modernização local adaptou atividades já existentes a um novo grau de modernismo.

maquinário da linha foi montado de modo a permitir a produção em pequenos lotes mais personalizados, ao invés dos grandes lotes homogeneizados do modelo fordista. Além disso, as melhorias feitas permitiram uma maior qualidade do produto final e um tempo de montagem médio mais curto. Obstante a isso os carros japoneses já saiam da linha de montagem com uma expectativa de vida inferior à média dos americanos, uma tendência que se disseminou em toda indústria e ficou conhecida como 'obsolescência programada'.

Somado a essas mudanças internas houve uma reestruturação dos fornecedores, conformando-os aos padrões de qualidade da companhia sem uma integração vertical literal como ocorria na Ford. Reflexo desse sistema de produção foi a adoção de um padrão logístico mais ágil e preciso capaz de atender aos pequenos lotes, reduzindo também drasticamente a área de estocagem e assim o desperdício de tempo e espaço, fazendo cair para minutos a velocidade de saída dos veículos. Nascia assim o JIT.

O JIT é um conjunto de princípios, ferramentas e técnicas que permitem que a empresa produza e entregue os produtos em pequenas quantidades,

2 O sobrenome da família Toyoda foi adaptado para Toyota por questões de marketing (Liker, 2005).

3 Para mais informações, ver dados da Automotive News Global Market Data Book ([s.d]) e Womack, Jones e Rood (2004, p. 32). 
com lead times curtos, para atender as necessidades específicas do cliente. Dito de formas simples, o JIT entrega os itens corretos na hora certa e na quantia exata. O poder do JIT é permitir que você corresponda às mudanças diárias da demanda, o que era precisamente o que a Toyota precisava (Liker, 2005, p. 43)

O sistema toyotista não chegou a ter o mesmo impacto do que o sistema fordista, pois enquanto o sistema fordista ajudou a moldar um homem e um modo de vida, o sistema toyotista foi adotado no todo ou em partes quando das crises estruturais dos anos de 1970. Ele vem no contexto do que se costumou denominar "acumulação flexível". Outros modelos como o saturnismo e volvismo também se fizeram nessa grande onda de mudanças.

A crise dos anos 1970 e as novas formas de possibilidade de ordenamento produtivo, como o Toytismo, fizeram prevalecer um novo modelo de ordenamento do espaço produtivo. As empresas agora iriam se deslocar para as periferias, fossem outro bairro, outra cidade ou outro país, daí o fenômeno dos policentrismos, cidades médias e dos NPI (novos países industrializados) onde poderiam explorar situações de organização do trabalho, preço da terra, facilidade de deslocamento e restrições legais mais favoráveis, fenômeno esse denominado por Harvey (1992) de ajuste espacial. Concomitantemente as sedes de comando e concepção das empresas escolheram os lugares mais centrais do globo para se instalarem, as cidades com maior conectividade e fluidez em seus territórios. Ambas as situações podem ser identificadas no caso da General Motors, que deslocou boa parte de suas plantas de montagem do interior dos EUA para o México, mantendo sua sede em Detroit e a Nike que tem uma cadeia produtiva segmentada por várias partes do Extremo Oriente.

A maior flexibilidade favorece a desintegração vertical das relações de proximidade entre dirigente e subcontratante, a troca contínua de informações e, portanto a proximidade espacial, que permite a interação e a regulação final do processo de processo de produção global (Benko, p. 29, 1996).

Essa segmentação reflete uma especialização vertical crescente, como explorou Hummels et al. (2001) refletindo especializações funcionais diversas em forma de distritos ou polos dos mais variados, a exemplo dos tecnopolos, como o Sillicon Valley, e distritos industriais, como o do condado de Orange, ambos nos EUA. Essa fragmentação espacial, reflexo da desintegração vertical da indústria fordista, acaba por gerar uma crescente necessidade de circulação para que a produção ainda consiga se operacionalizar, aumentando a necessidade de importação e exportação a todos os países (Santos, 1985, p. 55). 


\section{O que é o just-in-time?}

Até aqui foi esclarecido o momento histórico e em que condições surgiu o toyotismo e no seu bojo o JIT, e para seguirmos adiante vale um esclarecimento sobre o que é exatamente é JIT e como ele se encaixa no Sistema Toyota de Produção. Para isso, faremos uso das palavras de um de seus inventores: "Os dois pilares do Sistema Toyota de Produção são a autonomação e o just-in-time" (Ohno, 1997, p. 91). A autonomação (bakaioke), quer dizer, a automação com um toque humano, ideia herdada de Sakichi Toyoda, que a implementou em seu tear automático, que parava se o fio acabasse ou se rompesse, evitando danos e desperdícios desnecessários. O JIT é uma noção criada por Kiichirõ Toyoda após observar e estudar o supermercado americano onde os produtos eram repostos nas prateleiras assim que essas começavam a se esvaziar. A demanda do cliente é que determinava o ritmo de reposição. Ele notou que poderia transferir a noção de demanda anterior à oferta para o chão de fábrica, a chamada produção "puxada", que necessitava de uma linha rápida e sem estoques.

Just-in-time significa que, em um processo de fluxo, as partes corretas necessárias à montagem alcançam a linha de montagem no momento em que são necessárias e somente na quantidade necessária. Uma empresa que estabeleça esse fluxo integralmente pode chegar ao estoque zero (Ohno, 1997, p. 26).

A noção de cliente no JIT é esticada a cada passo da produção. $O$ cliente pode ser o posto de trabalho seguinte, ou a fábrica seguinte, até chegar ao consumidor final. Não se deveria produzir além da demanda, para que se evitasse a superprodução, o desperdício. A criação de estoques excessivos maquia o aparecimento de problemas, gera ocupação de espaço desnecessário na fábrica e com isso demandas para a administração dessa superprodução. Uma produção "puxada" leva a uma detecção imediata dos problemas na linha uma vez que essa é interrompida diante de uma falha em qualquer etapa. É a troca do chamado sistema batch and queue pelo lean.

O grande articulador e realizador dessas ideias concebidas pelos membros da família Toyoda foi o engenheiro mecânico chinês Taiichi Ohno. ${ }^{4}$ Ele foi o grande responsável pela implementação do JIT dentro da unidade fabril, reduzindo drasticamente os estoques internos da fábrica (principalmente os estoques das autopeças), o que fez com que o modelo Toyota muitas vezes se denomine ohnismo. Ele descreve o estoque como algo herdado da atividade agrícola dos países de clima frio, que deveria ser tido como desperdício no espaço industrial, sendo que a redução dos mesmos permitiu relevante redução de custos operacionais.

O JIT também só foi possível graças ao kanban, outro termo que se confunde com

Ohno trabalhou na Toyota Motors Company de 1943 a 1978. 
o próprio JIT, nomeado por vezes método kanban. Ohno (1997, p. 27/47) explica que "o kanban é o meio usado para transmitir informação sobre apanhar ou receber a ordem de produção [e complementa] o kanban é uma forma para atingir o JIT, sua finalidade é o JIT". Inicialmente, essa informação era passada por um cartão de identificação da peça, outra ideia que veio dos EUA, nascida na Lockheed (hoje Lockheed Martin), segundo Coriat (1994). Esse método veio a ser aprimorado pelo código de barra.

De fato, o JIT possibilitou à Toyota - e aqueles que adotaram seu sistema - uma expressiva economia. Com a redução da necessidade de estoque possibilitou-se uma planta enxuta, com reduções significativas em áreas ocupadas, gastos com a manutenção de armazéns, pessoal e maquinário especializado, como fica demonstrado nas descrições a seguir extraídas do livro de David Hutchins (1993, p. 25/31):

Igualmente relevante e a mais impressionante matéria relacionada ao JIT obtida da experiência na Toyota: na fábrica, com exceção dos veículos montados na linha, não havia estoque. Normalmente, seria de se esperar encontrar grandes pilhas de portas, painéis, para-choques, bancos, parabrisas, motores, caixas de câmbio, sistemas de transmissão etc. Na fábrica da Toyota, fora alguns itens de baixo valor, não havia nada. No lugar das pilhas, caminhões ou transportadores - continuamente voltam a linha de montagem e são descarregados, peça por peça para os veículos que estão sendo montados. Logo que um transportador é descarregado, outro toma seu lugar e o anterior retorna para o fornecedor, com esse tipo de produção, o mais estarrecedor é o fato de os veículos da linha de montagem não serem todos iguais $[\ldots]$.

O caso da fábrica de velas NGK. É impressionante porque visitei uma fábrica equivalente da Europa Ocidental, com o volume de saída similar, algumas semanas depois. Para o mesmo volume de saída, a fábrica japonesa tinha aproximadamente um quinto da área de produção de sua equivalente europeia.

A técnica do JIT foi difundida ao longo da década de 1960 para os fornecedores da empresa sendo totalmente estabelecido na cadeia produtiva em meados de 1970. Daí em diante, difundiu-se pelo Japão e em seguida às concorrentes das empresas no exterior, atingindo quase todas as que competem a nível global (Mccann, 2008). O JIT se tornou o aspecto mais popular do toyotismo, levando a uma confusão entre esses dois termos. Aos olhos dos geógrafos essa confusão fica ainda mais fácil, uma vez que o JIT é o aspecto do modelo com maior impacto na organização espacial, o mais visível; mas como podemos pensa-lo de um ponto de vista espacial? 


\section{O modelo logístico just-in-time como objeto de estudo da geografia}

Sendo o JIT um modelo de ordenamento logístico, ele pode ser compreendido como "um plano orientado e uma abordagem que visa criar um plano único para o fluxo de produtos e informações por de uma empresa" (Christopher, p. 2, 2011). Ele também pode representar "as estratégias (que podem ser competitivas), o planejamento e a gestão de transportes (que podem ser intermodais) assim como o armazenamento" (Silveira, 2011, p. 23). Ou ainda "deve ser entendida como um conjunto de atividades que orientam, em correlação com um fluxo de informações preciso, a movimentação de mercadorias dentro de uma rede produtiva completa" (Coró, 2003, p. 105), uma vez que é a própria "circulação [...] quem testemunha a eficácia da comunicação, mas isso significa que o movimento da informação que comanda a mobilidade dos seres e das coisas" (Raffestin, 1993, p. 203). Pela informação, o JIT orienta e organiza os fluxos que percorrem o território; ele é efetivamente anterior ao ato de transportar.

Assim, podemos compreender o JIT, e de forma geral a logística, como uma técnica, uma vez que estas podem ser "agrícolas, industriais, comerciais, culturais, políticas, $d a$ difusão da informação, dos transportes, da distribuição etc.; técnicas que aparentes ou não em uma paisagem, são, todavia, dados explicativos do espaço" (Santos, 1994, p. 57, grifo nosso). Assim as técnicas de distribuição, ou podemos dizer, logísticas, são tidas como dados explicativos do espaço. Infere-se assim que uma técnica logística, tal qual o JIT, pode nos servir como dado explicativo de espaços voltados à produção e ao consumo, uma vez que essa intenciona ordenar os fluxos materiais: sejam matérias-primas, produtos semi-industrializados, produtos finais, pessoas, assim como os fluxos imateriais (como dados sobre estoque e demanda especificações de entregas etc.). "As técnicas são um conjunto de meios instrumentais e sociais, com os quais o homem realiza sua vida, produz e, ao mesmo tempo, cria espaço" (Santos, 2009, p. 25). No entanto, essa forma de organização dos fluxos aparece apenas em associação a outras técnicas.

Outras técnicas essas que para Santos (1994) formam uma família de técnicas uma vez que toda nenhuma técnica tem existência autônoma ou solitária. O mesmo ocorre com o JIT que nasce junto ao kanban, kaizen e os 5S que compõe o sistema conhecido como toyotismo ou ohnismo. O toyotismo, por sua vez, vem integrar outras famílias de sistemas produtivos do movimento da acumulação flexível ou pós-fordistas. Essas técnicas se deram em concomitância e possibilitadas pelas novas condições do espaço global.

Esse espaço global, tido por Santos (1994, 2000, 2009) como mais intensivo em elementos técnicos, científicos e informacionais, é fruto de um casamento entre a ciência e a técnica a serviço do modo de produção hegemônico que é o capitalismo. Essa combinação que se difundiu pelos territórios do mundo no processo de globalização permitiu uma unicidade técnica em nível mundial como nunca a humanidade havia experimentado, e que permite a integração das economias nacionais favorecendo as multinacionais, que aumentam suas possibilidades de lucros e giro pelo acesso mais rápido e fácil a diversos territórios. Essa unicidade técnica, por sua vez, é fruto de uma 
difusão das técnicas hegemônicas que se dão em espaços globais caracterizados - entre outras coisas - por uma:

[...] aceleração de todas as formas de circulação e seu papel crescente na regulação das atividades localizadas, com o fortalecimento da divisão territorial e divisão social do trabalho; e a dependência deste em relação às formas espaciais e às normas sociais (jurídicas e outras) em todos os escalões (Santos, 1994, p. 47).

A circulação acelerada acaba por reforçar o poder das empresas mais dinâmicas, que tem mais condições de usar e implementar os sistemas de engenharia necessários para a crescente velocidade de giro das mercadorias e por conseguinte do capital (Santos, 1985, p. 83).

Assim, o meio técnico-científico-informacional é condição e ao mesmo tempo foi moldado por técnicas como o JIT, que é usado por atores globais que podem atuar com máxima eficiência em espaços mais inseridos no contexto da globalização. Essa inserção se faz quando o território, ou o lugar, oferece permeabilidade a essa técnica, oferecendo condições e estruturas favoráveis à sua inserção. Entre outras condições, pode-se destacar a possibilidade da localização das unidades fabris próximo às rodovias, portos e aeroportos com facilidade e rapidez de acesso a internet de alta velocidade e comunicação via satélite, que permita o controle geral do processo de logística. Em nível global, de forma análoga, o JIT é factível graças a uma unicidade técnica em portos, aeroportos e teleportos, sistemas de engenharia, que tornam possível o controle de fluxos graças às linguagens comuns como o inglês, o código de barras, o sistema internacional de pesos e medidas. "Apenas as informações que atingem um alto grau de codificação podem ser transmitidas a distância, como um software, um desenho CAD, um texto digitalizado, um conjunto de dados estruturados" (Coró, 2003, p. 107).

É claro que nem todas as pessoas ou firmas tem acesso igual a esse tipo de tecnologia, ou tem condições de desenvolvê-la. Assim, o JIT, só pode atingir os lugares ou regiões que permitem uma plena eficácia da técnica tomando uma forma espacial própria uma vez que "mudanças[s] técnica[s], mudança[s] organizacional[is] e mudanças[s] espacial[is] estão articuladas num único conjunto [...]" (Dias, 2007, p. 3).

Assim como ocorre com outras técnicas de ordenamento de fluxos, o JIT se espacializa, se revela no espaço, como uma rede, ou um conjunto de redes. Redes essas que são para Santos (1994, p. 13-14) "portadoras de informações, mercadorias, ideias, dinheiro, recados afetivos", e cuja "função fundamental é assegurar ligações, nos seus mais diversos aspectos". E que para Corrêa (1996, p. 107) trata-se de um certo número de ligações que interconectam uma variedade de localidades. Pode-se dizer que as redes na sua forma espacializada, as redes geográficas, são os diversos conteúdos que formam fluxos que interligam diversos pontos no espaço.

As redes, que dependem do conteúdo técnico do território para ter sua efetivação, 
com maior ou menor fluidez, são mais evidentes conforme a materialidade de seus conteúdos, de seus fluxos; quanto mais imateriais os fluxos mais voláteis podem ser as redes, se reorganizando a cada momento. Quanto mais dinâmica do ponto de vista tecnológico é a civilização material, mais se impõe o caráter deliberado na constituição de redes (Santos, 2009, p. 265).

Elas compõem um dos elementos significativos para interpretar o espaço como um todo, sobretudo as formas espaciais ligadas a corporações multifuncionais e multilocalizadas, que cada vez mais se organizam de forma reticular em escalas cada vez maiores, ligando pontos cada vez mais distantes. Corporações essas que, ao selecionar as formas reticulares que mais lhe convém, intensificam cada vez mais a seletividade espacial de suas localizações (Dias, 1994, p. 150). Como mostra Lencioni:

A multiplicidade e diversidade de redes nos dias atuais, mormente as relacionadas direta ou indiretamente à produção, se constituem em forças produtivas fundamentais de uma economia, cada vez mais globalizada. Essas redes expressam, antes de tudo, as relações de circulação do capital e é nessa expressão que evidenciam uma das dimensões do espaço: o espaço como meio, ou seja, o espaço como mediação necessária à reprodução do capital em escala globalizada (Lencioni, 2006, p. 67).

Tomando como pressuposto que:

A circulação e a comunicação são as duas faces da mobilidade. Por serem complementares, estão presentes em todas as estratégias que os atores desencadeiam para dominar as superfícies e os pontos por meio da gestão e do controle das distâncias. Falaremos de circulação cada vez que se trate de transferência de seres e de bens lato sensu, enquanto reservaremos o termo "comunicação" à transferência de informação. Ainda que, por mais útil que seja, essa distinção ambígua, uma vez que poderá dar a entender que há apenas a circulação e apenas comunicação. Na realidade, em todo "transporte" há circulação e comunicação simultaneamente (Raffestin, 1993, p. 200).

Podemos assim inferir que o JIT é uma técnica de ordenamento de fluxos materiais e imateriais, de logística, que apresenta uma forma reticular no espaço. Essa forma reticular se estabelece apenas em locais susceptíveis a alcançar os objetivos do "desperdício zero".

\section{Considerações finais}

Ao longo do texto, delineou-se a importância do JIT no contexto das mudanças estruturais ocorridas na economia e na organização do espaço produtivo mundial durante o século XX, e, assim, pode-se defini-lo como uma técnica. 
É importante compreender a dimensão das mudanças no sistema produtivo global no século XX que se deram antes na indústria automobilística, com Ford, e depois os Toyoda. Todas essas mudanças visavam reduzir o tempo de giro do capital, uma preocupação do mercador desde a Idade Média (Le Goff, 1979, p. 61-73).

Outro aspecto também importante a apreender na acumulação flexível, no que concerne ao JIT, é a capacidade atual da indústria automotiva de pulverizar suas unidades produtivas e/ou fornecedores pelo mundo buscando espaços que permitam maior lucratividade no conjunto da produção. Essa pulverização das cadeias produtivas das grandes multinacionais foi concomitantemente à redução crescente do custo dos transportes durante as últimas décadas, segundo Hummels (2007), Mas, para além disso, se tornou "operacionalizável" diante da evolução das técnicas de logística que, na concepção de Coró (2003, p. 105), devem ser interpretadas "como uma infraestrutura estratégica que, reduzindo as barreiras físicas e operacionais entre locais de produção e consumo, permite organizar a divisão do trabalho em escala global em ciclos produtivos espacialmente diferenciados". Esses ciclos produtivos espacialmente diferenciados alteram a noção de nacionalidade do produto, podendo conflitar com os interesses dos Estados nacionais.

Tomar o JIT, assim como outras formas de ordenamento de logística, como uma técnica que imprime certa lógica aos espaços, nos permite uma aproximação mais clara ao tentarmos compreender os espaços destinados à produção e à circulação. São espaços do imperativo da fluidez, dos fluxos codificados e seletivos (Santos, 2009; Tavares, 1995). Esses espaços do capital internacional, da economia internacional globalizada, espaços da globalização, onde os Estados nacionais e as grandes corporações estão presentes, muitas vezes em comunhão.

Esses espaços fluidos, que tendem ao imediato, são os que definem as principais linhas de força da competitividade e da racionalidade do capital, cada vez mais tecnificadas e informatizadas. Esses espaços da globalização são, sem dúvida, hegemônicos, mas estão longe de ser absolutos. Mesmo dentro de uma única cidade, especialmente nas metrópoles, há temporalidades e espacialidades diferentes do capital globalizado; há os espaços daqueles do tempo lento, às vezes em bairros próximos a modernas instalações empresariais (Santos, 2009).

A ideia de Toyoda, o JIT, se difunde e replica nos espaços corporativos, sejam os da produção material ou imaterial, em que o "no momento exato" se torna um dos elementos necessários à competitividade e à racionalização do tempo. Esse afinamento dos elementos do capital ao "zero desperdício" do tempo, visando o lucro privatizado, não sai sem custos ambientais sociabilizados, como já alerta Ludd (2005, p. 95).

Como podemos notar, os impactos espaciais do JIT - assim como os de outras formas de ordenamento logístico -, podem ser os mais diversos e significativos, cabendo aos geógrafos maior preocupação em esmiuçar os impactos reais, que têm sido ignorados por muitos, segundo Coe, Dicken e Hess (2008), e não só demonstrar os impactos positivos que podem causar ao setor produtivo. No entanto, essa análise não pode ser 
desligada de uma interpretação dos sistemas produtivos de forma mais ampla, a fim de se compreender a totalidade dos fenômenos espaciais.

\section{Referências}

AUTOMOTIVE NEWS, [s.d]. Disponível em: http://www.autonews.com/section/ datalist11. Acesso em: 17 abr. 2017.

BENKO, G. Economia, espaço e globalização na aurora do século XXI. São Paulo: Hucitec, 1996.

CHRISTOPHER, M. Logistics and supply chain management: creating valueadding networks. New York: Pearson Education Limited, 2011.

COE, N. M.; DICKEN, P.; HESS, M. Global Production Networks: realizing the potential. Journal of Economic Geography, Oxford, UK, n. 8, p. 271-295, 2008.

CORRÊA, R. L. Interações espaciais. In: CASTRO, I. E.; GOMES, P. C. C.; CORRÊA, R. L. Explorações geográficas. Rio de Janeiro: Bertand Brasil, 1997. p. 279-318. . Dimensões de análise de rede geográfica. In: Trajetórias Geográficas. Rio de Janeiro: Bertrand Brasil, 1996. p. 107-120.

CORIAT, B. Pensar pelo avesso: o modelo japonês de trabalho e organização. Rio de Janeiro: Revan/UFRJ, 1994.

CORÓ, G. Logística, economia global e desafios para o Made in Italy. In: MONIÉ, F.; SILVA, G. A mobilização produtiva dos territórios: instituições e logística do desenvolvimento local. Rio de Janeiro: DPEA, 2003. p. 99-142. (Coleção Espaços do desenvolvimento).

COUTINHO, L. O desenvolvimento urbano no contexto da mudança tecnológica. In: GONÇALVES, M. F. (Org.). O novo Brasil urbano: impasses, dilemas, perspectivas. Porto Alegre: Mercado Aberto, 1995. p. 41-62.

DIAS, L. C. Redes de informação, grandes organizações e ritmos de modernização. Etc... Espaço, Tempo e Crítica (Online), n. 2, v. 1, jun. 2007.

. Redes: emergência e organização. In: CASTRO, I. E.; GOMES, P. C. C.; CORREAA, R. L. (Org.). Geografia: conceitos e temas. Rio de Janeiro: Bertand Brasil, 1994. p. 141-164. 
FORD, H. Today and tomorrow. Reprint ed. Portland, OR: Productivity Press, 1988.

HARVEY, D. A condição pós-moderna. São Paulo: Loyola, 1992.

HUMMELS, D. Transportation Costs and International Trade in the Second Era of Globalization. Journal of Economic Perspectives, v. 21, n. 3, p. 131-154, 2007. .; ISHII, J.; YI, K.-M. The nature and growth of vertical specialization in world trade. Journal of International Economics, v. 54, n. 1, p. 75-96, 2001.

HUTCHINS, D. Just-in-time. Trad. S. M. Corrêa. São Paulo: Atlas, 1993.

LENCIONI, S. Da cidade e sua região à cidade-região. In: SILVA, J. et al. (Org.). Panorama da geografia brasileira. São Paulo: Annablume, 2006. v. 1. p. 65-76.

LE GOFF, J. Para um novo conceito de Idade Média. Lisboa: Estampa, 1979.

LIKER, J. K. O modelo Toyota: 14 princípios de gestão do maior fabricante do mundo. Porto Alegre: Bookman, 2005.

LUDD, N. A importância do carro na economia moderna. In: LUDD, N. (Org.). Apocalipse motorizado: a tirania do automóvel em um planeta poluído. São Paulo: Conrad, 2005. p. 15-32. (Coleção Baderna.)

MCCANN, P. Globalization and economic geography: the world is curved, not flat. Cambridge Journal of Regions, Economy and Society, Oxford, UK, n. 1, p. 351-370, 2008.

MOREIRA, R. Da região à rede e ao lugar: a nova realidade e o novo olhar geográfico sobre o mundo. Etc... Espaço, Tempo e Crítica (Online), v. 1, n. 1, p. 55-70, jun. 2007.

OHNO, T. O sistema Toyota de produção: além da produção em larga escala. Porto Alegre: Artes Médicas, 1997.

PONS, J. M. S.; BEY, J. M. P.; REYNÉS, M. R. M. Nuevas perspectivas para la geografía de los transportes: algunas aportaciones temáticas y conceptuales del nuevo milenio. In: SILVEIRA, M. R. (Org.). Circulação, transportes e logística. São Paulo: Outras Expressões, 2011. (Coleção Geografia em Movimento).

RAFFESTIN, C. Por uma geografia do poder. Trad. Marília Cecília França. São Paulo: 
Ática, 1993.

RUSHTON, A.; CROUCHER, P.; BAKER, P. The handbook of logistics and distribution management. London: Koren Page, 2010.

SANTOS, M. A natureza do espaço: técnica e tempo, razão e emoção. São Paulo: Edusp, 2009[1996].

Por uma outra globalização. São Paulo: Record, 2000.

Técnica, espaço e tempo. São Paulo: Edusp, 1994.

Metamorfoses do espaço habitado. São Paulo: Edusp, 1988.

Espaço e método. São Paulo: Edusp, 1985.

SILVEIRA, M. R. Geografia da circulação, transportes e logística: construção epistemológica e perspectivas. In: SILVEIRA, M. R. (Org.). Circulação, transportes e logística. São Paulo: Outras Expressões, 2011. (Coleção Geografia em Movimento).

SUTHERLAND, J. L. Logistics from a Historical Perspective. In:TAYLOR, G. D. (Org.). Introduction to logistics engineering. Nova York: CRC, 2009.

TAVARES, H. M. Novos espaços industriais: o papel do Estado. In: GONÇALVES, M. F. (Org.). O novo Brasil urbano: impasses, dilemas, perspectivas. Porto Alegre: Mercado Aberto, 1995. p. 203-216.

WOMACK, J. P.; JONES, D. T.; ROOS, D. A máquina que mudou o mundo: baseado no estudo do MIT sobre o future do automóvel. Rio de Janeiro: Elsevier, 2004.

WOOD, T. Fordismo, toyotismo e volvismo: os caminhos da indústria em busca do tempo perdido. Revista de Administração de Empresas, São Paulo, n. 32, n. 4, p. 6-18, 1992. 